\title{
correspondence
}

\section{Unemployed scientists}

SiR,-Your article (21 April, page 668) describing the plight of Soviet scientists who have been refused employment and have tried to carry on their work in isolation rang a familiar bell. But, although the world receives news of these unhappy people in the Socialist countries, no mention is made of the plight of hundreds of unemployed biologists, chemists, physicists, and mathematicians in the Free World.

Any science department in Canada which ventures to advertise a vacancy gets snowed under by anywhere from 75-400 applicants most of whom are underemployed and receive no professional recognition from their colleagues. Despite this, universities go on pretending that no such problem exists, and have not taken steps to expand their faculty to alleviate it. The unemployed scientist has no faculty union, cannot apply for research grants, cannot receive travel grants, and must work in isolation. He is barred from receiving unemployment assistance unless willing to seek any type of work, thereby relegating his professional career, for which he and his parents have paid dearly, to the status of a part-time hobby.

Every government adopts certain policies for eliminating its unwanted and superfluous citizens. The methods of the Socialist and Free-World countries differ only in superficial aspects. A doctoral student whom I taught at the University of Calgary sought suitable employment for five and a half years from 1968-73, before taking his life, leaving a widow and three small children. Can we truly say that such people have suffered any less than the 'refusniks' of the Soviet Union?

$$
\begin{aligned}
& \text { Yours faithfully, } \\
& \text { JAMES J. KLEIN }
\end{aligned}
$$

University of Regina, Saskatchewan, Canada

\section{Let $\boldsymbol{n}$ be the psammity}

SIR,-What is the quantity of which the mole is the SI unit? It is 'amount of substance' (in French quantité de matière). However, Newton's definition of mass was as quantity of matter (in Latin quantitas materiae), and the word 'substance' carries overtones of theology and mediaeval philosophy. It is only necessary to recall the snickers among scientists when 'amount of substance' was introduced, or the bewilderment of students who try to make sense of the expression, to realise that 'amount of substance' does not describe what it names, and that English needs a simple word for this quantity, as German has Stoffmenge.

Common speech does not have a word that can readily be extended to cover the concept, but several classical roots might yield a suitable word. Although grains of sand had been a Greek metaphor for uncountability, Archimedes in his Sand-Reckoner (Psammités in Greek) calculated the number of grains of sand that would fill the known universe. To replace 'amount of substance,' I propose 'psammity', evoking Archimedes' calculation and treated as if there were a Latin psammitia from which it derives, with combining form 'psammito-' and adjective 'psammitic'.

How would these be used? It is usual to write, "Let $m$ be the mass . . .", and only later need it be revealed that the unit will be the kilogramme. On the other hand, at present we write, "Let $n$ be the number of moles ...". If instead we write, "Let $n$ be the psammity...", the dimension of $n$ is clear, but the unit, whether mole, micromole, or pound-mole, need only be specified when numerical values are given. Again, when the density of a gas is expressed in moles per unit volume we must at present speak of molar density, but this would become psammitic density. Other uses of psammity follow by simple analogy with mass and length, where common usage already distinguishes the quantity from the unit.

\section{Yours faithfully, George S. KelL}

National Research Council, Ottawa, Canada

\section{Microprocessor myths}

SiR,- I fear that some of the 'myths' mentioned in Basil Zacharov's article on microprocessors (28 April, page 760) were actually fluffy and insubstantial.

It is true that microcomputers cost more than microprocessor chips; more, even, than naked minis. But what is of genuine importance is this. One can now buy-and pay for-only as little computing power as one actually needs, right down to a four function calculator costing \$7. No longer must one spend the $\$ 7$ every half hour in connection charges, and waste time keeping up on the latest system releases, just to be able to calculate small profundities on demand.

Microcomputer users may also spend inordinate amounts of time writing software, but after all, anyone making many small-scale runs, rather than engaging in massive, production number-crunching, must write a seemingly inordinate quantity of software (or spend almost as much time learning to use canned software). The microcomputer also has one overwhelming advantage with respect to the software investment: ownership and control. That control provides a modicum of assurance that one's heavy investment in software will not suddenly be destroyed or devalued at the whim of an outside party. The real question is: how can anyone afford not to use a computer small enough to own, whenever possible?

It is also true that microcomputers are not fast, complicated, and sophisticated like minis and mainframes, but the power of a pocket calculator is sufficient for a large class of tasks. A microcomputer system costing a mere $\$ 1,700$ is likely to be severely limited by the user's communication speed.

None of this is new. After all, that 'complex internal organisation' which allows a big mainframe to perform 'many concurrent activities' is customarily installed precisely so that the mainframe can simulate a hundred or a thousand small computers running at once, each serving a different user. Today, we can sometimes spare ourselves that nonsense, and simply purchase the hundred computers.

Small computing tasks have tended to be served inconveniently, expensively, and sometimes even with grudging arrogance, by traditional computer facilities. Microcamputers and LSI technology complete the low end of the continuum of computer powers. It should, therefore, not be hard to understand the microprocessor phenomenon. After all, it is practically one and the same with the calculator revolution. Even diehard advocates of mainframing everything have been known to use calculators.

Yours faithfully, PAUL Schick

University of Wisconsin-Madison, USA 